\title{
Effectiveness of Stress Management on Glycemic Control and Change of some of Mental Health Indicators (Depression, Anxiety, Stress, and Quality of Life) among Patients with Type 2 Diabetes
}

\author{
Faezeh Hosseinzade Saraej ${ }^{*}$ \\ Hamidreza Hatami² \\ Fariborz Bagheri ${ }^{3}$
}

\begin{abstract}
${ }^{*}$ Department of General psychology, Tehran science and research branch, Islamic Azad University, Tehran, Iran 2Department of General psychology, Imam Hossein University, Tehran, Iran ${ }^{3}$ Department of General psychology, Tehran science and research branch, Islamic Azad University, Tehran, Iran *Corresponding Author Email: hosseinzade.iau@gmail.com
\end{abstract}

\author{
Doi:10.5901/mjss.2016.v7n4p
}

\section{Abstract}

The present research aimed to determine effectiveness of stress management on glycemic control and change of some of mental health indicators (depression, anxiety, stress, and quality of life) among patients with type 2 diabetes. The present research is an applied research in sake of aim and a quasi-experimental research with pre-test and post-test in sake of data collection. The research sample consists of 19 patients with type 2 diabetes selected via convenient sampling method, and considered in two experimental (10) and control (9) groups in random. Then, the experimental group attended in training course of stress management which was held via behavioral-cognitive method during 12 sessions in 2 hours, that no intervention was applied on control group. The pre-test and post-test tools for both groups include hemoglobin A1c (HbA1c) blood test, the questionnaires of Depression, Anxiety and Stress Scale(DASS) and the short form of the World Health Organization Quality of Life (WHOQOL). The data were analyzed via covariance analysis test, that the analysis indicated that there was a significant difference between training stress management via behavioral-cognitive method and hemoglobin A1c (HbA1c) blood and depression, stress and quality of life at level( $P<0.05)$, yet there was no significant relationship between hemoglobin $\mathrm{A} 1 \mathrm{c}(\mathrm{HbA} 1 \mathrm{c})$ blood and anxiety. Hence, it can deduce that training stress management affects changing some mental health indicators and even Glycemic Control among patients with type 2 diabetes.

Keywords: type 2 diabetes; Glycemic Control; Stress Management; depression, stress, quality of life

\section{Introduction}

However, overview of the relationship between physical diseases and psychological variables in recent decades, it seems that such an issue has been drawn into attention by philosophers and physicians of ancient Greece, such that the Ancient Greeks believed that the man's physical health is influenced of his mental health, under which the cause for any disease was searched in individuals' lifestyle (Sandra,2005). This is of a great importance in today's world especially in developed and developing countries, because people's life in today's world differs from that of in the past. For instance, the rate of industrialization has increased and the rate of stress to people and their contact with hazardous chemical substances has intensified. In addition, nowadays, more people reach old age affected by chronic diseases (Sarafino,2006). For this, despite the past centuries that people used to die due to being affected by nutritional and infectious diseases, today chronic diseases such as cardiovascular disease, cerebral infarction, cancer, and diabetes, respiratory and renal diseases are the main reasons for mortality among individuals (Seward,2006). In the present research, Diabetes mellitus which has been called diabetes includes a group of common metabolic disorders that result in increase of hyperglycemia. These disorders have been classified to four groups including type 1 diabetes, type 2 diabetes, gestational diabetes and other specific types of diabetes. The basis for this classification lies on etiology proposed for each classification.

Metabolic regulation disorders might occur due to decreased insulin secretion, reduction of glucose by cells and increase in hepatic glucose production, and raise secondary pathophysiologic changes in different organs of body, imposing a huge pressure on the person affected by diabetes and health care system (Powers,2005). Diabetes is accounted as the most common chronic disease (Newsletter Medical Association, 2006). That the studies on diabetes 
keep increasing (Adili,Larijani\& Haghighatpanah, 2006), so that over 5000 scientific articles are being published per year (Hanas,2007). Type 1 diabetes and type 2 diabetes are thoroughly susceptible to effects of stress (Taylor, 2003), that there is a bilateral relationship between stress and disease. Physical diseases especially the chronic diseases are accounted as the stresses and important life events, such that role of stress has been specified in emergence of most of diseases. Random sequence of stress and disease might be in two ways: 1- a direct trajectory as the result of the changes that stress might raise in physiology of the human body, 2-an indirect trajectory that includes effect on health through the person's behavior (Sarafino, 2006). It seems that both these trajectories are active in diabetes. When the individuals are affected by stress, their adrenal glands including epinephrine and cortisol are released into the bloodstream. Epinephrine obliges the pancreas to a decrease in insulin production. Cortisol can increase glucose production by affecting liver and decrease use of glucose in body tissues. These biochemical reactions to stress harden the problem over blood sugar control in patients with diabetes (Goldeston,Kovacs, Obrosky, \& lengar,1995). In addition, emotional stress might intensify the behavioral changes to the extent that the person does not observe his diet, exercise and medication. This can raise disorder in glycemic control and hypoglycemia (Powers,2005). There are numerous discussions on the relationship between chronic diseases and Diabetes Mellitus and patients' mental problems. Aggression and depression are these patients' reactions against their diseases. Major outcomes of aforementioned mental problems include emergence of anorexia nervosa, diet confusion, not accepting insulin injections by patients, raising problem in control and treatment of diabetes. Lack of access to proper control of disease often can result in frustration or a state which is called diabetes burnout. This can result in poorer control of disease and anxiety and concern about the acute complications of disease (Snoek, \& Skinner,2006).

Anxiety: anxiety is another common problem followed by diseases, that secretion of Adrenal hormones (adrenaline and cortisol) that are called stress hormones increase under stress and anxiety that the patient has about his/her disease, whereby these hormones as antagonist of insulin intensify Hyperglycemia(Kazemzadeh,1996). Hence, detecting patients' mental problems and/or training a skill stress management program as a favorable approach can become beneficial for better control of disease and decrease and prevention of physical, mental and social problems and complications due to diabetes.

Stress management is called to a series of techniques and methods that is employed to reduce the stress experienced by individuals or increase their ability to cope with their life stresses(Quick \& Cooper,2003). These techniques are so diverse, including some behavioral methods such as relaxation, meditation, systematic desensitization or behavioral-cognitive methods such as coping skills training, assertive training, cognitive restructuring and psychosomatic(Michalsen, , Groossman, Lehmann, , Knoblauch, Paul, Moebus, Budde\& Dobos, 2005). The interventions via stress management have been employed in wide range of psychosomatic and physical diseases, of which it can refer to cardiovascular diseases, high blood pressure, AIDS, cancer, tension headaches, Irritable bowel syndrome IBS (Oneil,Jonnalagadda, Hopkins\& Kicklighter,2005).

\section{Literature Review}

There are a large body of studies at the area of each of research variables and their relationship with each other. Taylor (2003) has referred to results of 14 studies on the direction relationship between stress and poor control of diabetes. Further, the relationship between stress and different aspects pertaining to mental health including inter-personal communications, depression and other psychological frustrations has been confirmed(Shapiro,Astin,Bishop\& Cardova, 2005), such that high rate of stress and maladaptive coping skills are accounted as the risk factors for mental and emotional problems including depression and anxiety (Zolfaghari,Khani,Pourshahbaz,1998). In addition to rate of stress, the way for reaction to stress or coping styles taken by the individuals affected by chronic diseases is ofgreatimportance (Blings, Cronkite \& Moos, 1981, Penedo, Molton, Dahn, Shen, Kinsinger, Traeger, Siegel, Schneiderman \& Anton, 2006). Coping has been mentioned as the mediating factor between stress and physical or mental disorder. Concerning diabetes, studies grant support to the relationship between individuals' coping styles and stress and glycemic control. It has been specified that negative, avoidant and maladaptive coping with poor control of blood sugar (Nomura, Fujiomoto, Higashino, Denzumi, Miyagawa, Miyajima, Nada, Kkondo, Tada, Morishata, Saito, Ito \& Nakaya, 2000), and lack of physical, mental and social well-being and even healthy eating behaviors which are included of an important dimension of quality of life all affect quality of life (Snoek \& Skinner,2006). Quality of life especially health related quality of life is another issue which has been discussed in numerous studies. Lav et al. (2004) have referred to the relationship between better hemoglobin $\mathrm{A} 1 \mathrm{c}(\mathrm{HbA1c})$ and improvement in quality of life of patients with diabetes especially their mental dimension; further another research indicated that major complications of diabetes associate to quality of life especially health (Coffey, Brandle, Zhou, Marriott, Burke, Tabaei, Engelgan, 2006). Most of researchers have put an emphasis on 
necessity of implementation of intervention studies with the aim of affecting the aforementioned factors. The studies in recent years grant support to effect of psychological interventions derived from different approaches especially cognitive and behavioral techniques for patients with chronic disease. These interventions which are generally performed via group method include the trainings proposed to individuals about adjustment with disease and problems pertaining to it, suppression of stress due to disease and other life stresses, improvement of quality of life and mental health. For instance, Carrico et al.(2006) displayed a significant decrease in depression and coping based on denial through considering behavioral-cognitive stress management in trainings pertaining to treatment of patients affected by AIDS (Coffey,Brandle, Zhou, Marriott,Burke, Tabaei, Engelgan,2006). In a study by Carrico et al. (2002), 72 participants were considered in two experimental and control groups that their state- trait anxiety, conceptual stress and general health, body mass index, diet intake, and status of their daily activities were control by measuring amount of HbA1c blood. In addition to general trainings for diabetes, stress management including training progressive muscle relaxation and some behavioral and cognitive training was performed in experimental group.

Results of follow-up during 2, 4, 6 and 12 months after implementation of research indicated positive and stable effects of intervention on metabolic control and general health of participants, yet this research failed to display which individuals enjoy more stress management (Surwit, Tilburg, Zucker, McCaskill, Parekh, Feinglos, Edwards, Williams, Lane, 2002). Mohammad Hassan Davazdah Imami, Rasoul Roshan, Ali Mehrabi and Abbas Attari (2007) examined effect of treatment via behavioral-cognitive method on glycemic control and depression among patients with type 2 diabetes in two experimental and control groups.

Findings from Glycosylated hemoglobin $(\mathrm{HbA1c})$ were measured before three months after ending the intervention. After intervention, mean of the scores for experimental group than control group had been reduced to a large extent $(P<0.001)$. Further, after intervention, mean of depression scores in experimental group has been less than mean of depression scores in control group $(P<0.001)$. They concluded that training stress management can affect decrease in depression and glycemic control among patients with type 2 diabetes. It should be noted results of all the studies at this area do not confirm this effect, that further studies especially at the countries such as Iran with high rate of diabetes are required. With regard to role of stress in process of glycemic control among patients with type 2 diabetes and the relationship between stress and some of psychological problems among these patients including anxiety and depression.

\section{Research objective}

The present research was designed and performed so as to determine effectiveness of stress management on glycemic control and some mental health indicators among patients with type 2 diabetes. With regard to what mentioned above, the present research has tested effect of stress management training on one of chronic diseases such as diabetes .

\section{Method}

This research is practical in terms of objective. It is a half-pilot study with test and control groups under a pre and post test design for both groups. The research sample consists of 19 patients with type 2 diabetes selected via convenient sampling method, and considered in two experimental (10) and control (9) groups in random. Then, the experimental group attended in training course of stress management which was held via behavioral-cognitive method during 12 sessions in 2 hours, that no intervention was applied on control group. After doing the tests, data were collected and analyzed in two descriptive and inferential statistics. In descriptive section, mean and standard deviation have been used. In inferential statistics, covariance analysis via software SPSS was examined to compare and examine difference of groups in pre-test and post-test.

\section{Research instruments}

1- Hemoglobin Alc: Hemoglobin (HbAlc) refers to a protein that is glycated on $\mathrm{N}$ - terminal valine through beta chain in an irreversible way, recognized as the most important sign for survey of glycemic control in a long period (Tanaka et al. 2007). Hence, measuring Glycated hemoglobin (HbAlc) in blood is a laboratory method which is used to evaluate glycemic control in a long period. Different studies have indicated efficiency of common evaluation of HbAlc in all the patients with diabetes especially in type 1diabetes (insulin-dependent diabetes) and pregnant women. Indeed, effect of type of treatment and improvement in the control of blood glucose can be perceived in reduction of HbAlc. This indicator has been reported as percent, that it can be interpreted regarding determined normal range by any laboratory. Amount of $\mathrm{HbAlc}$ in a person with diabetes can be undergone a good glycemic control to the rate of $2 \%$ upper than normal limit.

2- The Depression Anxiety Stress Scales (DASS): this scale has been developed by Loi Band (1995) to measure 
depression, stress and anxiety in individuals. Cronbach s alpha coefficient for sub-scales of this test in sample group (717) include: depression (0.81), anxiety (0.73) and stress (0.81).

\section{The short form of the World Health Organization Quality of Life (WHOQOL)}

The original version of this questionnaire is inter-cultural scale that has been developed in 1994 by an attempt by a number of researchers under supervision of world health organization to evaluate quality of life of individuals, in which quality of life is assumed with 24 dimensions which are considered in 6 ranges. Cronbach split- half coefficient and internal consistency in a sample group (302) among Shiraz university students have been reported 0.87 and 0.84 , respectively. Further, retest half splitting has been obtained equal to 0.67 , and the results pertaining to validity have been reported via general health questionnaire. Iranian version of this questionnaire which has been used in the present research consists of 26 questions, that the participants give response to the questions in this questionnaire via Likret scale. Yet, the questions 4, 3 and 26 are scored from 5 to 1 in an inverse way and the questions 1 and 2 are not calculated in scoring. Thus, range of general scores will range from 24 to 120. Further, in factor analysis of the Iranian version despite original version which has included four sub-scales, three subscales have been obtained, so that the life environment and social relations develop a subscale altogether.

\section{Findings}

To analyze data, research data have been considered in two descriptive and inferential sections and undergone analysis. In the first section with common elements of descriptive statistics, statistical indicators of mean and standard deviation in two experimental and control group at pre-test and post-test were considered.

\subsection{First section: descriptive analysis}

Table 1. Descriptive indicators for control group in two pre-test and post-test groups $\left(n_{1}=n_{2}=19\right)$

\begin{tabular}{llll}
\hline Indicator & & Mean & Standard deviation \\
\hline \multirow{2}{*}{ HbA1C } & Pre-test & $6 / 31$ & $1 / 78$ \\
\cline { 2 - 4 } & Post-test & $6 / 88$ & $1 / 65$ \\
\hline \multirow{2}{*}{ Depression } & Pre-test & $5 / 66$ & $2 / 50$ \\
\cline { 2 - 4 } & Post-test & $6 / 02$ & $2 / 42$ \\
\hline \multirow{2}{*}{ Anxiety } & Pre-test & $4 / 88$ & $3 / 17$ \\
\cline { 2 - 4 } & Post-test & $4 / 77$ & $2 / 63$ \\
\hline \multirow{2}{*}{ Stress } & Pre-test & $9 / 33$ & $5 / 12$ \\
\cline { 2 - 4 } & Post-test & $9 / 44$ & $4 / 44$ \\
\hline \multirow{2}{*}{ Quality of life } & Pre-test & $82 / 88$ & $5 / 48$ \\
\cline { 2 - 4 } & Post-test & $80 / 33$ & $6 / 20$ \\
\hline
\end{tabular}

The information in table 1 has represented mean and standard deviation for indicators of HbAlC including depression, anxiety, stress and quality of life at pre-test and post-test stages for control group. As shown, the difference on scores at pre-test and post-test is negligent in indicators.

Table 2. Descriptive indicators for experimental group at two pre-test and post-test stages ( $n 1=n 2=19$ )

\begin{tabular}{llll}
\hline Indicator & & Mean & Standard deviation \\
\hline \multirow{2}{*}{ HbA1C } & Pre-test & $6 / 44$ & $1 / 46$ \\
\cline { 2 - 4 } & Post-test & $5 / 57$ & $1 / 43$ \\
\hline \multirow{2}{*}{ Depression } & Pre-test & $7 / 60$ & $6 / 04$ \\
\cline { 2 - 4 } & Post-test & $3 / 30$ & $2 / 62$ \\
\hline \multirow{2}{*}{ Anxiety } & Pre-test & $6 / 80$ & $5 / 2$ \\
\cline { 2 - 4 } & Post-test & $4 / 50$ & $2 / 83$ \\
\hline \multirow{2}{*}{ Stress } & Pre-test & $10 / 40$ & $4 / 37$ \\
\cline { 2 - 4 } & Post-test & $6 / 70$ & $4 / 02$ \\
\hline \multirow{2}{*}{ Quality of life } & Pre-test & $78 / 40$ & $13 / 63$ \\
\cline { 2 - 4 } & Post-test & $89 / 90$ & $12 / 26$
\end{tabular}


The information in table 2 has represented mean and standard deviation of indicators of $\mathrm{HbA1C}$ including depression, anxiety, stress and quality of life at pre-test and post-test stages for experimental group. As shown, there is a huge difference between scores at pre-test and post-test stages at all the indicators of HbA1C including depression, anxiety, stress and quality of life. Hence, intervention by training stress management in indicators of HbA1C including depression, anxiety, stress and quality of life has been effective among patients with type 2 diabetes.

\subsection{Inferential analysis}

In this section, covariance analysis has been used to test research hypothesis. The research hypothesis indicates that training stress management affects reducing blood sugar, depression, anxiety, stress and quality of life among patients with type 2 diabetes.

\subsection{Overview of inferential data}

Levene test has been used on the assumption over homogeneity of variances of the two groups in the dependent variables in different stages of testing, that the results have been proposed in table 3 .

\subsection{Overview of Equality of Variances}

Table 3. Overview of Equality of Variances (Levene test)

\begin{tabular}{ccccc}
\hline & $F$ & Df1 & Df2 & Sig \\
\hline HbA1C & $0 / 442$ & 1 & 17 & $0 / 515$ \\
\hline Depression & $1 / 26$ & 1 & 17 & $0 / 277$ \\
\hline Anxiety & $0 / 409$ & 1 & 17 & $0 / 531$ \\
\hline Stress & $2 / 763$ & 1 & 17 & $0 / 115$ \\
\hline Quality of life & $2 / 049$ & 1 & 17 & $0 / 170$ \\
\hline
\end{tabular}

As shown in table 3, the value of significance level indicates that the data have not questioned the variance error. Indeed, results from Levene test to examine homogeneity of variance in groups indicated that both groups are homogenous in sake of variance, indicating the reliable results.

\subsection{Overview of significance of research hypothesis}

To determine effect of training stress management in indicators of HbAlC including blood sugar, depression, anxiety, stress and quality of life among patients with type 2 diabetes, covariance analysis was fulfilled, that the summary of results has been represented in tables below.

Table 4. summary of results of covariance analysis to determine effect of training stress management in indicators of HbAlC including blood sugar, depression, anxiety, stress and quality of life among patients with type 2 diabetes

\begin{tabular}{lccccc}
\hline Dependant variable & $F$ & Df & $\eta^{2}$ & $\Delta$ & Sig \\
\hline HbA1C-pre-test & $42 / 75$ & 1 & $0 / 728$ & 1000 & $0 / 001$ \\
Group membership & $42 / 75$ & 1 & $0 / 728$ & 1000 & $0 / 001$ \\
\hline Depression-pre-test & $12 / 624$ & 1 & $0 / 441$ & $0 / 915$ & $0 / 003$ \\
Group membership & $21 / 750$ & 1 & $0 / 576$ & $0 / 992$ & $0 / 001$ \\
\hline Anxiety--pre-test & $32 / 94$ & 1 & $0 / 673$ & $1 / 00$ & $0 / 001$ \\
Group membership & $2 / 70$ & 1 & $0 / 145$ & $0 / 340$ & $0 / 120$ \\
\hline Stress--pre-test & $32 / 93$ & 1 & $0 / 673$ & $1 / 00$ & $0 / 001$ \\
Group membership & $9 / 33$ & 1 & $0 / 368$ & $0 / 818$ & $0 / 008$ \\
\hline Quality of life--pre-test & $10 / 53$ & 1 & $0 / 397$ & $0 / 861$ & $0 / 005$ \\
Group membership & $10 / 72$ & 1 & $0 / 401$ & $0 / 867$ & $0 / 005$ \\
\hline
\end{tabular}

Results of table 4 indicate that there is a significant difference between training stress management via behavioral- 
cognitive method and Blood sugar ( $\mathrm{HbAlc})$, depression, stress and quality of life at $(\mathrm{P}<0.05)$, yet there is no significant difference between training stress management via behavioral-cognitive method and anxiety. Hence, it can deduce that training stress management affects changing some indicators of mental health and glycemic control among patients with type 2 diabetes.

\section{Discussion and Conclusion}

In the present research, there is a significant difference between training stress management via behavioral-cognitive method and Blood sugar ( $\mathrm{HbAlc})$, depression, stress and quality of life at $(P<0.05)$, yet there is no significant difference between training stress management via behavioral-cognitive method and anxiety. Hence, it can deduce that training stress management affects changing some indicators of mental health and glycemic control among patients with type 2 diabetes.

This research can be elaborated via two points: firstly, it was specified that training stress management via behavioral-cognitive method can cause reducing secretion of cortisol in response to stress by affecting hypothalamicpituitary-adrenal axis (Hammerfald,Eberle, Grau,Kinsperger,Zimmermann,Ehlert\&Gaab,2006. Since cortisol by affecting liver causes increasing glucose production and reducing its use in body tissues, role of stress management trainings in reducing and controlling blood glucose is specified especially among patients with type 2 diabetes (Goldeston,Kovacs, Obrosky, \& lengar,1995). In addition to Neuro- hormonal explanation in the present research, it can examine role of Neuro- hormonal explanation in patients' follow-up with treatment diets and Diabetes Specific Quality of Life associated to diabetes. Emotional stress can intensify the behavioral changes in a way that the person gives up his diet, exercise and medication, affecting the amount of blood glucose in an indirect way (Powers,2005. Results of this research indicated that the stress management training has worked out successful in affecting quality of life of respondents. Hence, it can say that these individuals after receiving a training effective in coping with stress and healthy lifestyle enabled to modify their lifestyle for a favorable adjustment with diabetes and improvement of blood glucose on metabolic control and quality of life in type 2 diabetic patients. This problem has been probably effective in reducing emotional problems among these patients. Effect of intervention of these problems in a discussion is examined on next hypotheses. With regard to obtained results, it seems that the proposed training has not enjoyed sufficient power for significant effect on anxiety of participants. Since there is a close relationship between stress, anxiety and depression, these results might indicate a special dynamism between the variables (Sadock\& Sadock,2007). Barlow's attitude has been toward the relationship between anxiety and depression, stating that the individuals in exposure with life stresses and problems experience degrees of anxiety (Sadock\& Sadock,2007. By increasing these problems and bottlenecks so far as their effect goes beyond the person's tolerance, the amount of anxiety will intensify reaching to a state of helplessness. Indeed, anxiety is a mix of different emotions and recognitions that has embed in mine as a cognitive-emotional network (Barlow,2002). In this regards, anxiety has been mentioned as a cognitive-emotional structure that has been combined of a high negative emotion, lack of sense of control and a change of attention to a state of self-preoccupation (Grigsby, Anderson, Freedland, Clouse \& Lustman, 2002). With regard to high prevalence of anxiety among patients with type 2 diabetes and its relationship with low control of blood sugar (Bakhshipour, Dejkam, Mehryar \& Birashk, 2004). The mentioned states include sense of lack of control and preoccupation especially in relationship with diseases of the person and the problems arisen from his disease among patients with type 2 diabetes, resulting in hopelessness and depression. This point is consistent with Barlow's view on emergence of depression followed by anxiety. Barlow has stated about treatment and effect of interventions in this way that firstly depression symptoms in physiological, emotional and cognitive dimensions reduce and the emotional and cognitive symptoms of anxiety at deeper stages of treatment improve, because anxiety gets close to trait in this attitude, mentioned as a concept close to the concept of neurotism. Hence, it should be noted that results of this research confirm this theory, that more time and effort are required to change anxiety among participants.

As the sample size is not big in this research, and a unit scale has been used to measure depression, anxiety and stress, taking precaution is required. Despite result of this research, Heidari (2003) observed a significant difference between anxiety level in pre-test and post-test in experimental group by implementation of behavioral-cognitive treatment on adolescents with type 2 diabetes. Yet the intervention employed in this research has been considered as a special treatment for anxiety of patients, that a special scale has been used to measure anxiety, that is, Spielberger's State-Trait Anxiety Inventory ( Heydari,2004).

Surwit et al. (2002) in "Stress management improves long-term glycemic control in type 2 diabetes" indicated that trait anxiety among these patients has not predicted response to treatment, as a result the patients with high anxiety have not been improved via the treatment, i.e. reducing anxiety and improving glycemic control have been mentioned two 
separate issues. Rubin (2006) in his research Stress and depression in diabetes stated that depression treatments can come effective for all people especially people with diabetes. In this regards, he has recommended a special treatment based on behavioral-cognitive method for patients with diabetes with adaptive coping styles (Rubin, 2006). To sum up, results indicated that training stress management came effective in a better glycemic control among individuals and reduction of some psychological problems including stress and depression. Further, a big improvement has been indicated in quality of life of respondents. In other words, it seems that training stress management as a comprehensive program based on behavioral-cognitive approach for adults can come effective for the patients. With regard to economic, social and psychological effects of diabetes on individuals, families and community, the results of this research can be used for patients with diabetes and experts in diabetes. An emphasis has been put on the necessity for access by experts in diabetes and patients with diabetes to psychologists as a member of team American Diabetes Association (2008). Nonetheless, due to high prevalence of diabetes and some other chronic diseases and lack of psychologists and experts to a sufficient number, training stress management in group during a short-term can be effective helping for some of problems among the patients with diabetes.

Low sample size can be mentioned as one of the limitations in this research, that it requires taking precaution in conclusion and generalization of results. Lack group therapy has been mentioned as the other limitation. However, the participants sustain on their treatment in both groups, it has been suggested considering different groups in addition to control group to receive different training or treatment so as to compare the results. Hence, it is suggested to consider a bigger sample group based on the method of this research and results from it so as to reevaluate the results. Long-term follow-up to determine long-term effects of intervention and sustainability of results is required. Further, implementation of similar research on individuals with chronic diseases and comparison of their results with the results of this research seem required.

\section{References}

Adili, F., Larijani, B., \& Haghighatpanah, M. (2006). Diabetic patient: psychological aspects. Annals New York Academy of Sciences, 1084, 329-349.

American Diabetes Association (2008). Standards of Medical Care in Diabetes. Diabetes Care V 31, Supliment 1, 315- 358.

Bakhshi pour Roodsari, Abbas, Dejkam, Mahmoud, Mehryar, AH and Birashk, B. (2004 ). Structural relationships between dimensions of anxiety disorders and depression DSM-IV and the size of the model. Journal , 36, pp. 76-63 .

Barlow, D. H. (2002). Anxiety and its disorders. 2nd ed. Ney york: Guilford Press

Blings, A. G, Cronkite, R. C., \& Moos, R. H. (1981). Social- environmental factors in unipolar depression: Camparisons of depressed paints \& non depressed controls. Journal of Abnormal Psychology, 22, 119- 133.

Coffey, J. T.; Brandle, M.; Zhou, H.; Marriott, D.; Burke, R.; Tabaei, B.P.; Engelgan,(2006). Reduction in depressed mood and denial coping during cognitive behavioral stress management with HIV- positive gay men treated with HAART. Annual of Behavioral Medicine, 31, 155-164.

Hammerfald, K.; Eberle, C.; Grau, M.; Kinsperger, A.; Zimmermann, A. Ehlert, U. \& Gaab, J. (2006). Persistent effects of cognitivebehavioral stress management on cortisol responses to acute stress in healthy subjects- A randomized controlled trial. Psychoneuroendocrinology, 31, 333-339.

Hanas, Ragnar (2006 ). Insulin-dependent diabetes in children, adolescents and adults. Trans-Amir Kamran Niko Sokhan \& Masoomeh Eghbal jo. Tehran : Abi Publication.Heydari, F. (2004). The effect of cognitive-behavioral therapy to help control diabetes and reduce emotional disorders in children and adolescents with type 1 diabetes, unpublished MA thesis. Teacher Training University : Faculty of Psychology and Educational Sciences .

Kazemzadeh Atoofi , M. (1996). Application of relaxation in the metabolic control of blood glucose in patients with insulin-dependent diabetes. MA thesis . University of Medical Sciences, Tehran Psychiatric Institute .

Goldeston, D. B.; Kovacs, M.; Obrosky, D. S. \& lengar, S. (1995). A longitudinal study of life events and metabolic control among youth with insulin-depndent diabetes mellitus. Health psychology, 14, 409- 414.

Goldeston, D. B.; Kovacs, M.; Obrosky, D. S. \& lengar, S. (1995). A longitudinal study of life events and metabolic control among youth with insulin-depndent diabetes mellitus. Health psychology, 14, 409- 414.

Grigsby, B. A.; Anderson, R. J.; Freedland K. E.; Clouse R. E. \& Lustman, P. J. (2002). Prevalence of axiety in adults with diabetes: a systematic review. Journal of Psychosomatic Research, 53, 1053-1060

Michalsen, A.; Groossman, P.; Lehmann, N.; Knoblauch, N. T.; Paul, A.; Moebus, S.; Budde, T. \& Dobos, G. J. (2005). Psychological quality- of- life outmomes from a comprehensive stress reduction and lifestyle program in patients with coronary artery disease: results of a randomized trial. Psychother Psychosom, 74, 344- 352.

Newsletter Medical Association ( 2006). Message from the Chairman of the Medical Council on the occasion of World Diabetes Day . Site Iranian physicians . 2006 :www.pezeshkan.ir

Nomura, M.; Fujiomoto, K.; Higashino, A.; Denzumi. M.; Miyagawa, M.; Miyajima, H.; Nada,. T. ;Kkondo, Y.; Tada, Y.; Morishata., T.; Saito, K.; Ito, S.; \& Nakaya, Y. (2000). Stress and coping behavior in patient with diabetes mellitus. Acta Diabetol, 37, 61- 64. 
Powers, A. C. (2005). Diabetes mellitus, In L. D. Kasper (Ed in chief): Harrison's principles of internal medicine. Volume II. McGrow- Hill.

Penedo, F.J.; Molton, I.; Dahn, J.R; Shen, B.J.; Kinsinger, D.; Traeger, L.; Siegel S.; Schneiderman N.; Antoni, M. (2006). Arandomized clinical trial of group based cognitive-behavioral stress management in localized prostate cancer. Development of stress management skills improves quality of life and benefit finding. Annals of Behavioral Medicine, 31(3), 261-270

Quick, J. C. \& Cooper, C. L. (2003). Stress and strain. Oxford: Health press.

Rubin, R. R. (2006). Stress and depression in diabetes, In V. A. Fonseca (Ed), Clinical diabetes: Translating research in to practice (pp 269-280). Sunders Elsevior Inc.

Sadock, B. J. \& Sadock V. A. (2007). Daplan and Sadock's synapsis of psychiatry. (10th ed). Lippincott Williams \& Wilkins.

Sandra, M. (2005). Stress management as an adjunct treatment in patients identified with coronary artery disease: a program design. $A$ doctoral dissertation. Florid: Carlos Albizu University.

Sarafino, Edward , P . (2006). Health Psychology. Trans- a group of translators, supervised E. MIRZAEE . Tehran: Roshd publication( 2002).

Seward, Brian Luke . (2006). Stress management . trans- Mehdi Gharache Daghi. Tehran: Paykan publication ( 1997).

Shapiro, S.L.; Astin, J.A.; Bishop, S. R. \& Cardova, M. (2005). Mindfullness based stress reduction for health care profetionals. International Journal of Stress Management, 12, 164- 176.

Snoek, F. J. \& Skinner, T. C. (2006). Psychological aspects of diabetes management. Medicine, 34: 2, 61- 63.

Snoek, F. J. \& Skinner, T. C. (2006). Psychological aspects of diabetes management. Medicine, 34: 2, 61- 63.

Surwit, R. S.; Van Tilburg, M. A.; Zucker, N.; McCaskill, C. C.; Parekh, p.; Feinglos, M. N.; Edwards, C. L.; Williams, P. \& Lane, J. D. (2002). Stress management improves long-term glycemic control in type 2 diabetes. Diabetes Care 25, 30- 34.

Taylor, S. (2003). Health Psychology. (5 $5^{\text {th }}$ ed). McGraw Hill.The DCCT Research Group (1993). The effect of intensive treatment of diabetes on the development and progression of long-term complications in insulin dependent diabetes mellitus. N Engl J Med, 32, $977-986$

Zolfaghari, F, Mohammad Khani , P. Pour shahbaz , A. ( 1998). Study of coping strategies, self -efficacy concept and attitude to life events in the two groups of Iranian neurotic and normal . Journal , 11, pp. 43- 53. 